\title{
Ausforming and Marforming of a Cu-Zn26.3-Al3.9 Shape Memory Alloy
}

\author{
J. Spielfeld, E. Hornbogen and M. Franz* \\ Ruhr-University, Institute for Materials, 44780 Bochum, Germany \\ * University of Zagreb, Institute for Mech. Engineering, 10000 Zagreb, Croatia
}

\begin{abstract}
A copper-based shape memory alloy with $M_{s}$ below ambient temperature is investigated in four different conditions:

1) As betatized.

2) Ausformed at $800^{\circ} \mathrm{C}$ and at $780^{\circ} \mathrm{C}$, subsequently quenched.

3) Marformed by different amounts of true plastic deformation at temperatures below $M_{f}$.

4) Mechanically cycled (ausformed and as betatized state). The stress amplitudes $\Delta \sigma_{a}$ are chosen in the range between pseudo yield stress $R_{p p}$ and conventional yield stress $R_{p 0.2}\left(R_{p p} \leq \sigma_{a} \leq R_{p 0.2}\right)$. Different metallographic measurements are conducted to describe changes in microstructure and transformation behaviour. Ausforming results in a high defect density (dislocations, anti-phasedomain boundaries) in the ordered austenite. Cu-rich $\alpha$-precipitates at grain boundaries are observed. The $M_{s}$ temperature is lowered significantly. The conventional yield stress is raised. By marforming various defects and crystallographic disorder are generated in the martensite. They are responsible for suppression of the diffusion-less reverse transformation in the case of high amounts of true plastic deformation. Above a critical number of mechanical cycles of the ausformed alloy the martensitic as well as the reverse transformation take place in a two step mode which stays stable even in the following DSC cycles. An explanation can be based on the induction of defects which nucleate an additional type of diffusionless transformation.
\end{abstract}

\section{INTRODUCTION}

The transformation temperatures as well as the chemical composition of the chosen alloy are summarised in table 1. Six temperature ranges can be distinguished if shape memory alloys are thermomechanically treated. In the present study an alloy has been investigated in four of these six tem-

Table 1: Chemical composition and transformation temperatures of the investigated alloy (e/a=1.42). The maximum DSC-peak temperatures $\left(M_{m}\right.$ and $\left.\dot{A}_{m}\right)$ are added.

\begin{tabular}{|c|c|c|c|c|c|c|c|c|c|c|}
\hline Composition & $\mathbf{C u}$ & $\mathbf{Z n}$ & Al & Temperatures & $\mathbf{M}_{\mathbf{f}}$ & $\mathbf{M}_{\mathrm{s}}$ & $\mathbf{M}_{\mathbf{m}}$ & $\overline{\mathbf{A}_{\mathbf{s}}}$ & $\overline{\mathbf{A}_{\mathbf{f}}}$ & $\mathbf{A}_{\mathbf{m}}$ \\
\hline$w t-\%$ & 69.8 & 26.3 & 3.9 & \multirow[t]{2}{*}{${ }^{\circ} \mathrm{C}$} & \multirow[t]{2}{*}{-37} & \multirow[t]{2}{*}{-17} & \multirow[t]{2}{*}{-20} & \multirow[t]{2}{*}{$\overline{-12}$} & \multirow[t]{2}{*}{-3} & \multirow[t]{2}{*}{-5} \\
\hline$a t-\%$ & 66.8 & 24.4 & 8.8 & & & & & & & \\
\hline
\end{tabular}

perature ranges (table 2), namely in the range of pure ausforming [2], pure marforming [3] and in addition in the range of stress-induced transformation and ausforming in the region where additional thermally activated phase-transformations (precipitation, massive transformation) occur.

The purpose of such thermo-mechanical treatments is a modification of the transformation behaviour and the consequent shape memory properties or an increase in strength of the material. Strength implies yield stress, tensile stress uniform elongation etc. The two sets of properties are interrelated in practical applications: high strength is usually required in addition to a well defined transformation behaviour. The purpose of the present paper is the analysis of the interrelation between these two sets of properties. 
Table 2: Different temperature ranges in which a thermo mechanical treatment of shape memory alloys can take place. The ranges which are discussed in the paper are marked with: $\Rightarrow$.

\begin{tabular}{|c|l|l|l|}
\hline No. & Treatment & $\begin{array}{l}\text { Temperature } \\
\text { Range }\end{array}$ & Description \\
\hline \hline $\mathbf{1}$ & $\Rightarrow$ pure ausforming & $T_{1} \geq M_{d}$ & $\begin{array}{l}\text { deformation of stable austenite } \\
(\beta-\text { phase) }\end{array}$ \\
\hline $\mathbf{2}$ & $\Rightarrow$ pure ausforming (precipitates) & $T_{2} \geq M_{d}$ & $\begin{array}{l}\text { deformation of two phases ( } \beta- \\
\text { phase }+\alpha-\text { precipitates) }\end{array}$ \\
\hline $\mathbf{3}$ & strain induced martensite & $A_{f} \ll T_{3}<M_{d}$ & $\begin{array}{l}\text { formation of martensite from } \\
\text { plastic deformed austenite }\end{array}$ \\
\hline $\mathbf{4}$ & $\Rightarrow$ stress induced martensite & $M_{s}<T_{4}<T_{3}$ & $\begin{array}{l}\text { Martensite is formed from } \\
\text { austenite (stress-induced). No } \\
\text { prior true plastic deformation } \\
\text { of austenite takes place. }\end{array}$ \\
\hline $\mathbf{5}$ & $\begin{array}{l}\text { deformation of two phases } \\
\text { (austenite+martensite) }\end{array}$ & $M_{f}<T_{5} \leq M_{s}$ & $\begin{array}{l}\text { The residual austenite is me- } \\
\text { chanically transformed into } \\
\text { martensite. Reorientating } \\
\text { the thermally induced } \\
\text { martensite. }\end{array}$ \\
\hline $\mathbf{6}$ & $\Rightarrow$ pure marforming & $T_{6} \leq M_{f}$ & $\begin{array}{l}\text { (pseudo plastic) reorientation } \\
\text { of martensite and subsequent } \\
\text { true plastic deformation. }\end{array}$ \\
\hline
\end{tabular}

\section{AUSFORMING}

Pure ausforming (table 2, no. 1) implies a plastic deformation of the stable austenite $(\beta)$. For the introduction of lattice defects for the brass-type alloys two regions have to be distinguished:

The high temperature range between melting temperature and ordering temperature [6] [5] and the deformation of the ordered alloys. In all cases it is impossible to suppress order even if plastic deformation occurs at temperatures where this order is present. The procedure: hot rolling at $800^{\circ} \mathrm{C}$ and subsequent rapid quenching leads to a slight decrease in the transformation temperatures (figure 1). This decrease is accompanied by a corresponding increase in the pseudo-yield stress (figure 2). It is remarkable, that the same conditions show a high increase in yield-stress and tensile strength of the material. The microstructural changes are analysed by a combination of light- and transmission electron mi-

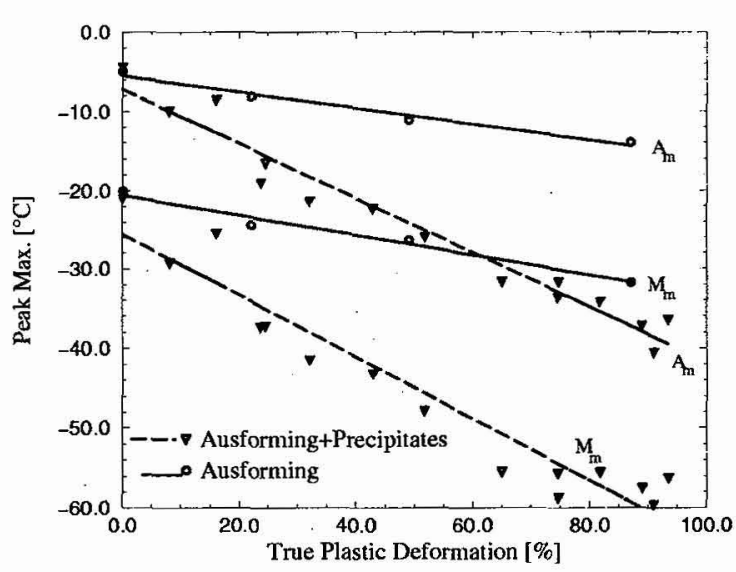
croscopy. Light microscopy provides an indication for the deformation of highly elongated grains. This implies a lack of long-range recrystallisation. Transmission electron microscopy provides evidence for the formation of three dimensional dislocation networks and a sub-grain structure which 
leads to a moiré inside the grains (figure 2 right). These are the features which are responsible for the high work hardening, the high strengthening effect which is provided by this method.

These results can be summarised in figure 2 left), where the drop of the martensite temperature corresponds to the increase in the pseudo yield-stress while at the same time the tensile strength is increased considerably.
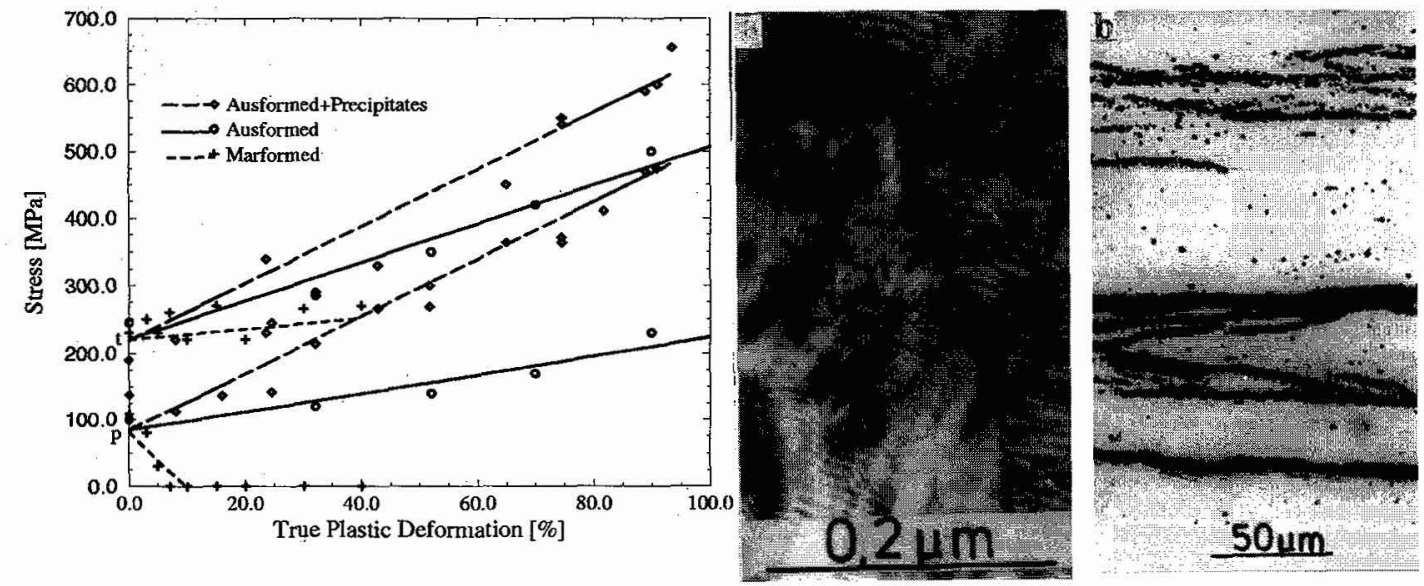

Figure 2: Left: Results of the stress-strain-tests. Ausformed and nnarformed. Right: Micrographs of the ausformed alloy: a) Defect structure (Moire, TEM). b) Optical micrograph showing elongated grains effected by pure ausforming.

\section{MARFORMING}

The same alloy has been deformed at temperatures below $M_{f}$, which implies the temperature of liquid nitrogen (table 2, no. 6). Figure 3 shows the change in transformation temperatures for the martensite $\rightarrow$ austenite reverse transformation as function of the amount of deformation.

In the undeformed state the structure has completely reverted into austenite until it has reached ambient temperature. This transformation temperature is considerably raised already after a small amount of plastic deformation (5\%). At amounts of deformation of less than $10 \%$ the temperature range of reverse transformation is brought up into the temperature range where diffusion is already considerable.

This implies that a complete change in the transformation mechanism occurs. At higher amounts of deformation the marten-

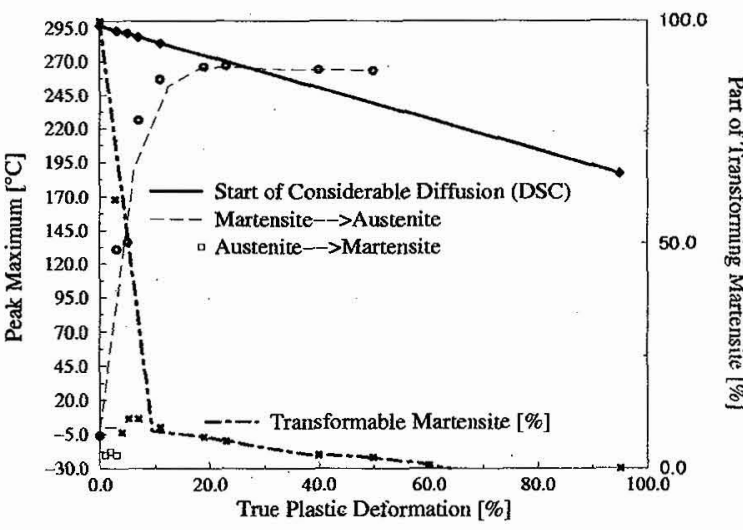
site is rendered untransformable. The martensite has to be heated up to the temperature range above $300^{\circ} \mathrm{C}$, where a thermally activated new nucleation of the $\beta$-phase is required. 
Additionally the amount of austenite, which is formed during the reverse transformation depends on the amount of deformation. It follows from figure 3, that martensitic retransformation extends only up to $10 \%$ deformation. At higher amounts there is no martensitic retransformation. This implies that the martensite is stabilised by lattice-defects (dislocations). Stress-strain-tests conducted at ambient temperature confirm these results (figure 4). The onset of stress induced martensitic transformation in the undeformed state is lowered by small amounts of deformation. Above $\varphi=7.5 \%$ the martensite fails after small amounts of additional plastic deformation. The lowering of the transformation stress can be explained by the presence of residual martensite from the primary plastic deformation (marforming), which is aiding the transformation during the subsequent tensile stress at ambient. temperature.

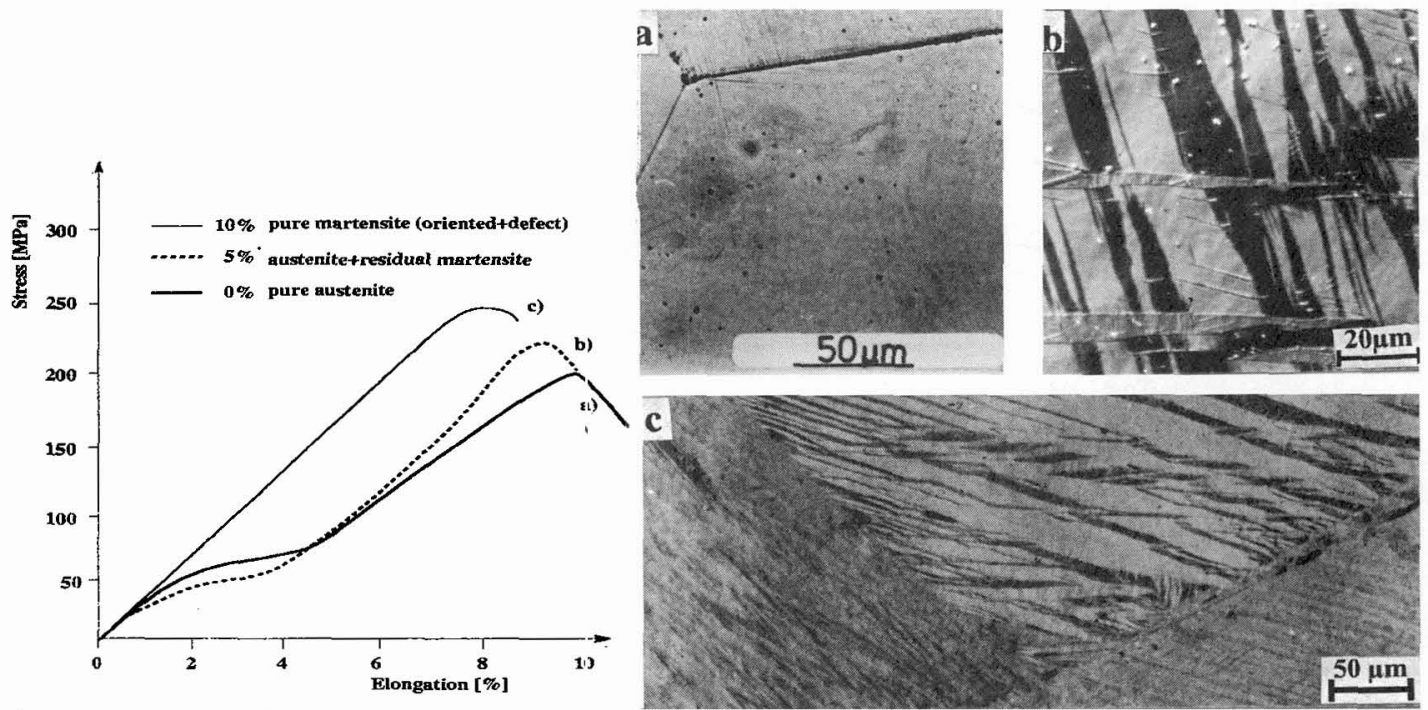

Figure 4: Stress-strain curves after different axnounts of marforming. a) $0 \%$ b) $5 \%$ c) $10 \%$. The corresponding micrographs (LM) a), b) and c) are combined on the right side.

\section{AUSFORMING AT LOWERED TEMPERATURES}

Lower ausforming temperatures in brass-type alloys $(T=$ $780^{\circ} \mathrm{C}$, table 2 , no. 2) lead either to an additional formation of the $\alpha$-phase or to formation of an intermetallic compound -for example $\gamma$-brass type- for zinc and aluminium rich alloys [4]. Under these conditions only a part of the microstructure is transformable. The analysis of the thermal transformation cycles shows a considerable drop of the transformation temperatures. This decrease is more pronounced than for pure ausforming (figure 1).

A possible explanation for this is, in addition to the lattice defects which have been introduced (dislocations, antiphase-domain boundaries), the presence of the finely dispersed particles as an obstacle to formation of martensite. Copper-rich $\alpha$-particles increase the zinc concentration in the surrounding matrix. This may be an additional reason

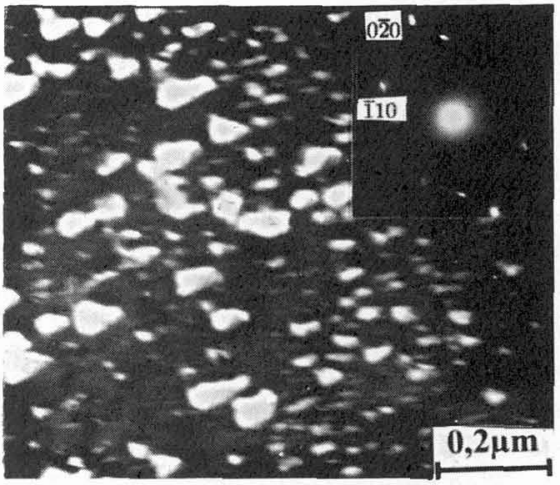

Figure 5: TEM-micrograph. $\alpha$-precipitates in the $\mathrm{B} 2$ ordered $\beta$-matrix. for the lowering of the transformation temperatures [1]. 


\section{STRESS INDUCED TRANSFORMATION}

Finally the alloy was investigated in the range of stress induced transformation just above $M_{s^{-}}$ temperature (table 2, no. 4). The mechanical treatment for our alloy can be conducted at ambient temperature. The stress-strain curves show a plateau, which is associated with stress-induced transformation (see figure 4, curve a)). The reversion is not complete if the stress is relaxed (figure 6 right).
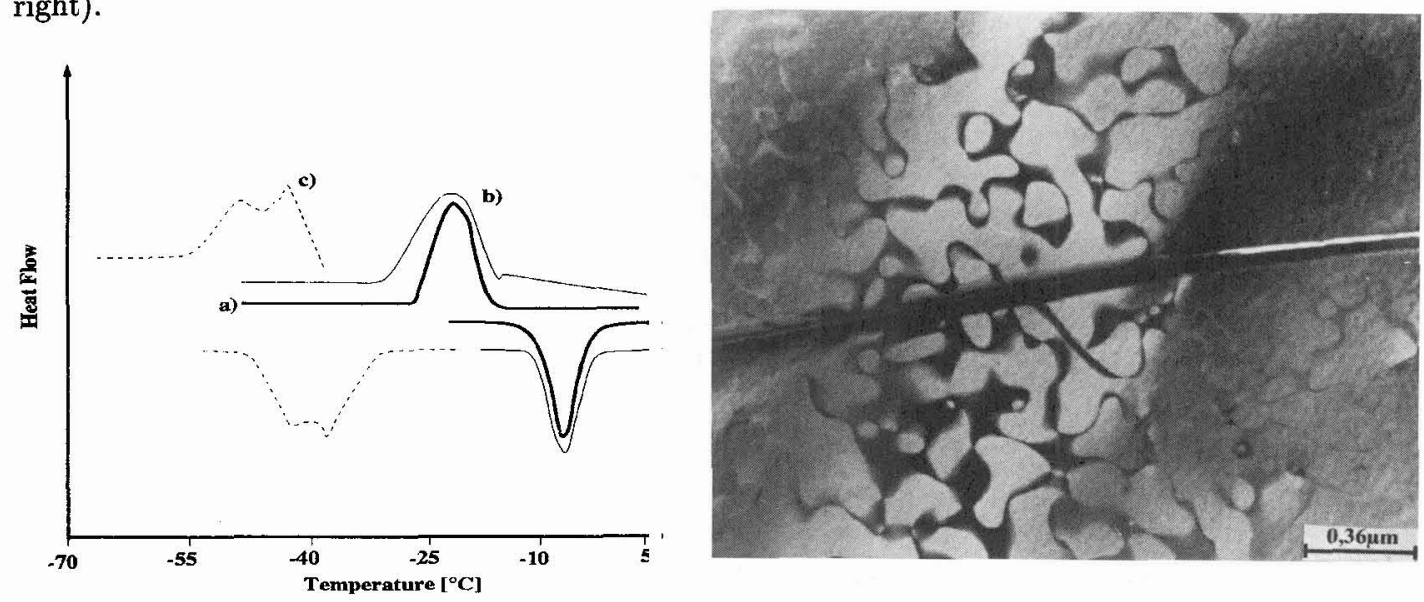

Figure 6: Left side: Thermal DSC-cycles for: a) Alloy as betatized. b) Elongated to $6 \%$ and reversed. c) After ausforming with $\varphi=60 \%$ and mechanical cycling (207MPa, 50 cycles). Right: TEM-micrograph. After an elongation of $6 \%$ and reversion a martensite needle is left in the austenite. Thermal anti-phasedomain boundaries (apdb) provide evidence for the ordered matrix. No strain-induced apdb are visible.

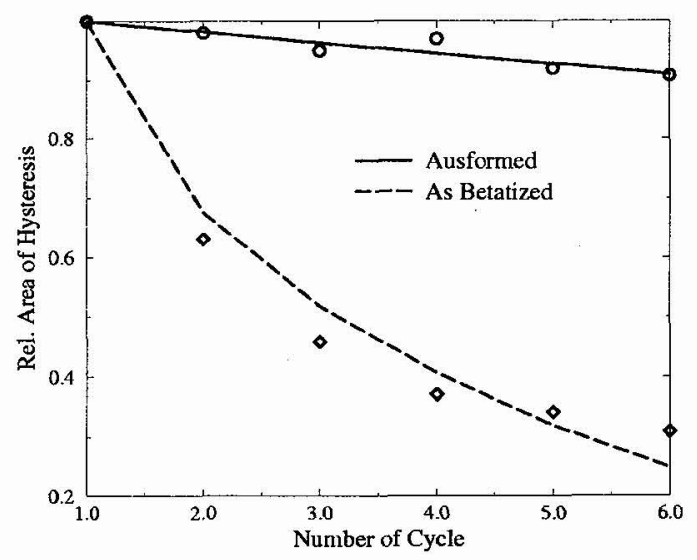

Figure 7: Reduction of the hysteresis effected by mechanical cycles. Dashed line: As betatized material. Solid line: Ausformed at $780^{\circ} \mathrm{C}$ by an amount of $\varphi=60 \%$.

The DSC-experiment (figure 6 left) shows the difference between the untreated alloy (as betatized, curve a)) and the same condition which has undergone stress induced transformation by one mechanical cycle (curve b)). This provides evidence for a pre-martensitic effect. This effect is observed only for the first thermal (DSC) cycle. At subsequent cycles it is removed. This provides evidence for the fact that a certain type of defect is produced by stress induced transformation but removed by subsequent thermal cycles. This must be a special type of defect, for example rearrangements in the domain boundaries of less than one atomic spacing.

Finally the condition which has been ausformed at the lower temperature (with $\alpha$-precipitates (see table 2, no. 2) and the as-betatized condition have been exposed to repeated mechanical cycles. Two remarkable results have been observed:

The reduction of mechanical hysteresis by an increasing number of cycles shows figure 7 for both types of prior treatment. The as-betatized alloy shows a much higher drop in hysteresis as compared 
to the ausformed one. This implies a greater stability of the latter against the accumulation of new structural defects.

Repeated mechanical cycling in the range of the stress-induced transformation produces a subsequent transformation behaviour which is highly interesting: Figure 6 left, DSC-curve c) shows that a two-stage transformation from austenite into martensite and a corresponding reverse transformation takes place. This type of transformation is stable against repeated thermal transformations. This observation implies that a permanent structural change has been induced. That is different from what we have shown earlier, where the preceding transformation was removed by the first DSC-cycle. No local change in the chemical composition can have taken place under the experimental conditions. Therefore mechanically-induced defects must be responsible. An explanation is that stable defects, probably dislocations, are introduced, which favour the transformation of a pre-martensitic stage preceeding the subsequent martensitic transformation. The structure of this phase is still unknown. Its formation is closer to second order while martensite is a typical first order transformation. We designate this phase as p-phase (pre-martensitic).

In summary these investigations show that a wide variety of defects can be introduced by thermomechanical treatments into copper-based alloys. These defects have considerable effects on the transformation behaviour. It is of great practical importance that they can lead to favourable combinations of strength and transformation behaviour, as it is required for example for fatigue resistance.

\section{Acknowledgements}

We gratefully acknowledge the support of the VOLKSWAGEN-STIFTUNG (VW-FOUNDATION, I70283) and the DEUTSCHE FORSCHUNGSGEMEINSCHAFT (DFG Ho 325/33-2). Thanks are due to Dr. D. Treppmann (Ruhr-Universität Bochum, Lehrstuhl Werkstoffwissenschaft) for useful discussions.

\section{References}

[1] M. Ahlers. ON THE STABILITY OF THE MARTENSITE IN $\beta-$ CU-ZN ALLOYS. Scripta Met., (8):213-216, 1974.

[2] M. Franz and E. Hornbogen. Ausforming of a $\beta-\mathrm{Cu} \mathrm{Zn} 24 \mathrm{Al} 9$ Shape Memory Alloy. Z. Metallkd., (86):31-34, 1995.

[3] E. Hornbogen. AUSFORMING AND MARFORMING OF SMA. In proc.: Int. Conf. on Displ. Phase Transf. and their Appl. in Mat. Eng., University of Illinois., May 1996 (to be published).

[4] S. Longauer et al. The shape memory effect of the two-phase $\alpha / \beta$ structure of the Cu-Zn-Al alloy. Metallic Materials, (30):355-367, Jan. 1992.

[5] K. Marukawa et al. Short Range Ordering and Stabilization of the Martensite Phase in Copper Alloys. In ICOMAT 1995 proc., pages 841-846. les èditions de physique, 1995.

[6] R. Rapacioli and M. Ahlers. Ordering in Ternary $\beta$-Phase $\mathrm{Cu} \mathrm{Zn} \mathrm{Al} \mathrm{Alloys.} \mathrm{Scripta} \mathrm{Met.,}$ (11):1147-1150, 1977. 